$1-1-2020$

\title{
Insights to improve social and behavior change programming through a focus on the attributes of behaviors
}

Breakthrough RESEARCH

Follow this and additional works at: https://knowledgecommons.popcouncil.org/departments_sbsr-rh How does access to this work benefit you? Let us know!

\section{Recommended Citation}

Breakthrough RESEARCH. 2020. "Insights to improve social and behavior change programming through a focus on the attributes of behaviors," Programmatic Research Brief. Washington, DC: Population Council. 


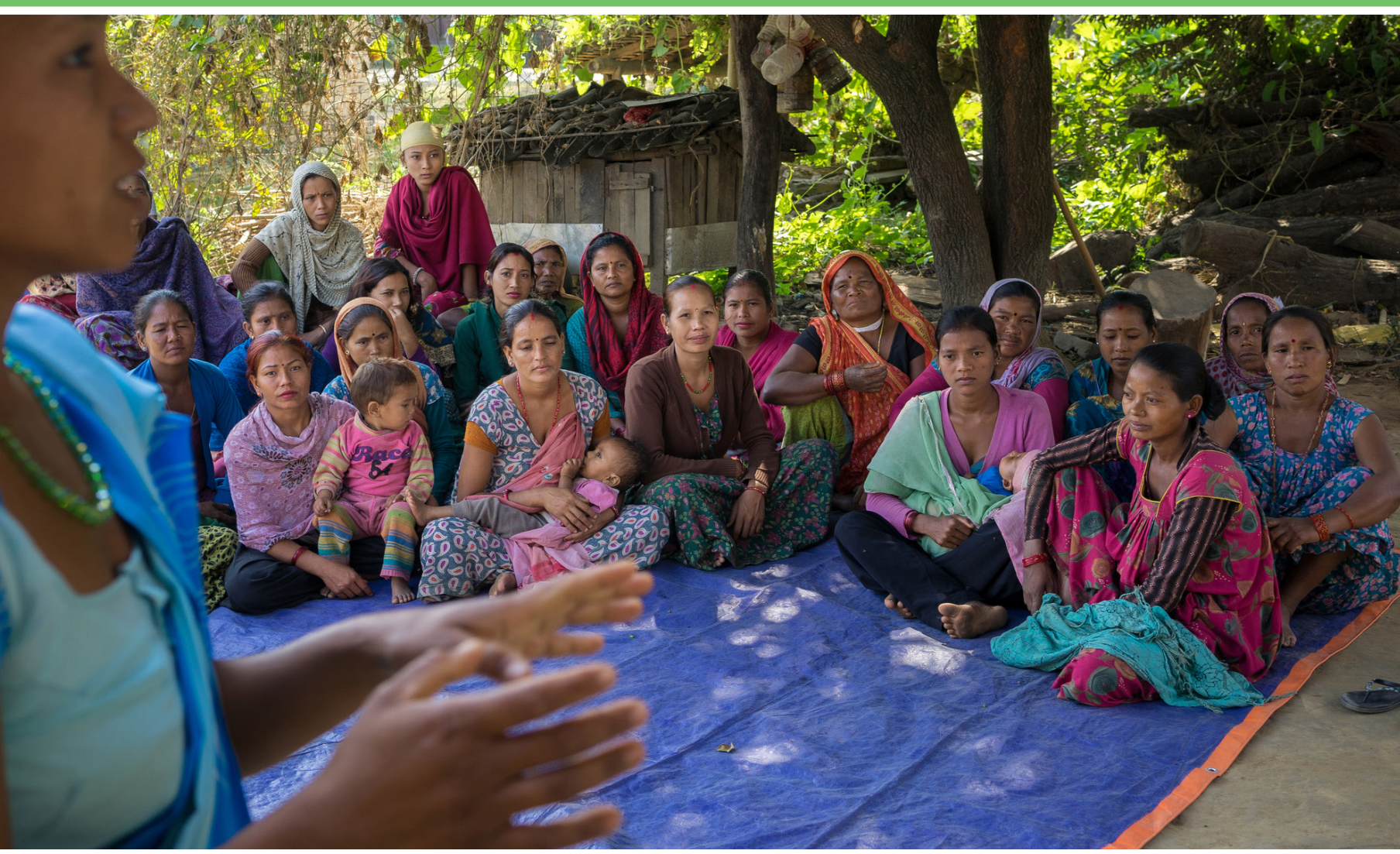

\section{Insights to Improve Social and}

\section{Behavior Change Programming Through a Focus on the Attributes of Behaviors}

Behavior change is complex and can be a challenging programmatic objective to achieve in any context, requiring a clear understanding of why people engage in behaviors in the first place. Tackling it from an unconventional perspective, however, may lead to fresh insights that can help inform the design of social and behavior change (SBC) programs and maximize their success. This brief describes the process and insights produced from Breakthrough RESEARCH's evidence review on attributes of behaviors.

\section{KEY POINTS}

In developing SBC programs, consider attributes of behaviors that are being targeted, rather than an exclusive focus on the characteristics of the target population.

Consider more universally applicable attributes of behaviors-repeatability, dependency, complexity, and time/opportunity cost-when designing SBC approaches. 



\section{TABLE 2. DEFINITIONS AND CRITERIA FOR MORE UNIVERSALLY APPLICABLE ATTRIBUTES}

Attributes

Repeatability

Refers to how often the actions that make up a particular behavior must be taken and at what intervals.

Behaviors that must be repeated very often require a decision-making process at each instance, that is different than behaviors for which decisions must be made only occasionally or once.

Note: Repeated behaviors with relatively little variation in the process require limited new learning and could become habitual or automatic over time.
Questions that Could Help Identify if an Attribute Applies to a Behavior

- Is the behavior repeated over short time intervals (e.g., daily)?

- Is the behavior repeated over longer time intervals (e.g., weekly or monthly)?

- Does the behavior require adherence to a schedule?

- Does the behavior require repeated decision-making?

- Is the behavior related to periodic cycles (e.g., seasonal weather patterns)?

\section{Illustrative Examples of Behaviors that Fit an Attribute}

Hand washing at critical times, use of insecticidetreated bed nets, use of contraceptives, and use of routine medications (e.g., antiretroviral therapies), among others.

\section{Dependency}

Refers to the degree to which performing the behavior requires direct assistance or cooperation from others.

Note: This definition excludes any social support that may be required to do the behavior, since this may be contextually dependent.
- Must individuals receive assistance from others to perform the behavior?
Women's use of male condoms (another person must put on the condom during intercourse), medical treatments (e.g., vaccines) which require medical personnel to administer the medication, and facility-based childbirth/delivery.

\section{Complexity}

Refers to the extent to which the behavior requires multiple deliberate decision-points (i.e., points where individuals must consciously select between alternative behavioral options); if it requires very specific knowledge or skills to implement that may require training to acquire; or if multiple steps that must be performed in a particular order.
- Does the behavior involve a deliberative decision process (either at one point or several)?

- Does the behavior require specific skills and/or knowledge to implement?

- Does the behavior involve multiple sequentially-ordered steps to achieve the outcome?

- Is the behavior one that is especially likely to be subject to technological or other shifts that could change the knowledge and skills required to implement the behavior?
Administering insulin injections, tuberculosis therapy, or managing multiple medications and their potential interactions.

\section{Time/Opportunity Cost}

Refers to the extent to which a behavior requires an amount of time that individuals may need to change their daily routines or forego other activities such as employment, regardless of their context.
- Does the behavior require a large amount of time to implement?

- Is the amount of time required for the behavior great enough that it would likely require deviation from one's normal routine?
Repeated antenatal care visits or use of clinic-based health services for child immunizations. 
TAKING THE LESS

CONVENTIONAL PERSPECTIVE

OF FOCUSING ON BEHAVIORAL

ATTRIBUTES MAY LEAD TO

FRESH INSIGHTS THAT CAN

HELP INFORM THE DESIGN OF

SBC PROGRAMS AND MAXIMIZE

THEIR SUCCESS.

\section{Applying more universally applicable attributes to select USAID accelerator behaviors}

In order to better understand how the universally applicable attributes might apply to health outcomes and behaviors across a range of different health areas and how this might inform SBC programmatic decisions, we applied the criteria above to each of the selected USAID accelerator behaviors. For example, in Table 3, caregivers seeking a full course of timely vaccinations for infants and children under two years of age is considered to be a repeatable behavior (highlighted by the dark blue tint) because vaccinations must be repeated (in some cases over relatively long-time intervals), requires an adherence to a schedule, and requires that caregivers repeatedly make the decision to have the infant or child vaccinated. This table lays out some examples applying behavioral attributes to select health outcomes. It also shows how some behaviors share attributes (e.g., both vaccination and modern contraceptive use have elements of complexity requiring deliberative decision making), suggesting that perhaps they could be influenced by similar programmatic approaches.

\section{Programmatic strategies that have addressed select behavioral attributes}

Once we understand how certain attributes apply to particular behaviors, the next questions are typically "so what?" and "what does this mean for programs?". To address these questions, the evidence review aimed to explore whether certain types of SBC intervention approaches have been documented as successful in addressing behaviors that share particular attributes. For example, are mass media campaigns, which often focus on reminders to enact particular behaviors, effective for behaviors that are classified as having high repeatability? Are behaviors with high levels of complexity particularly

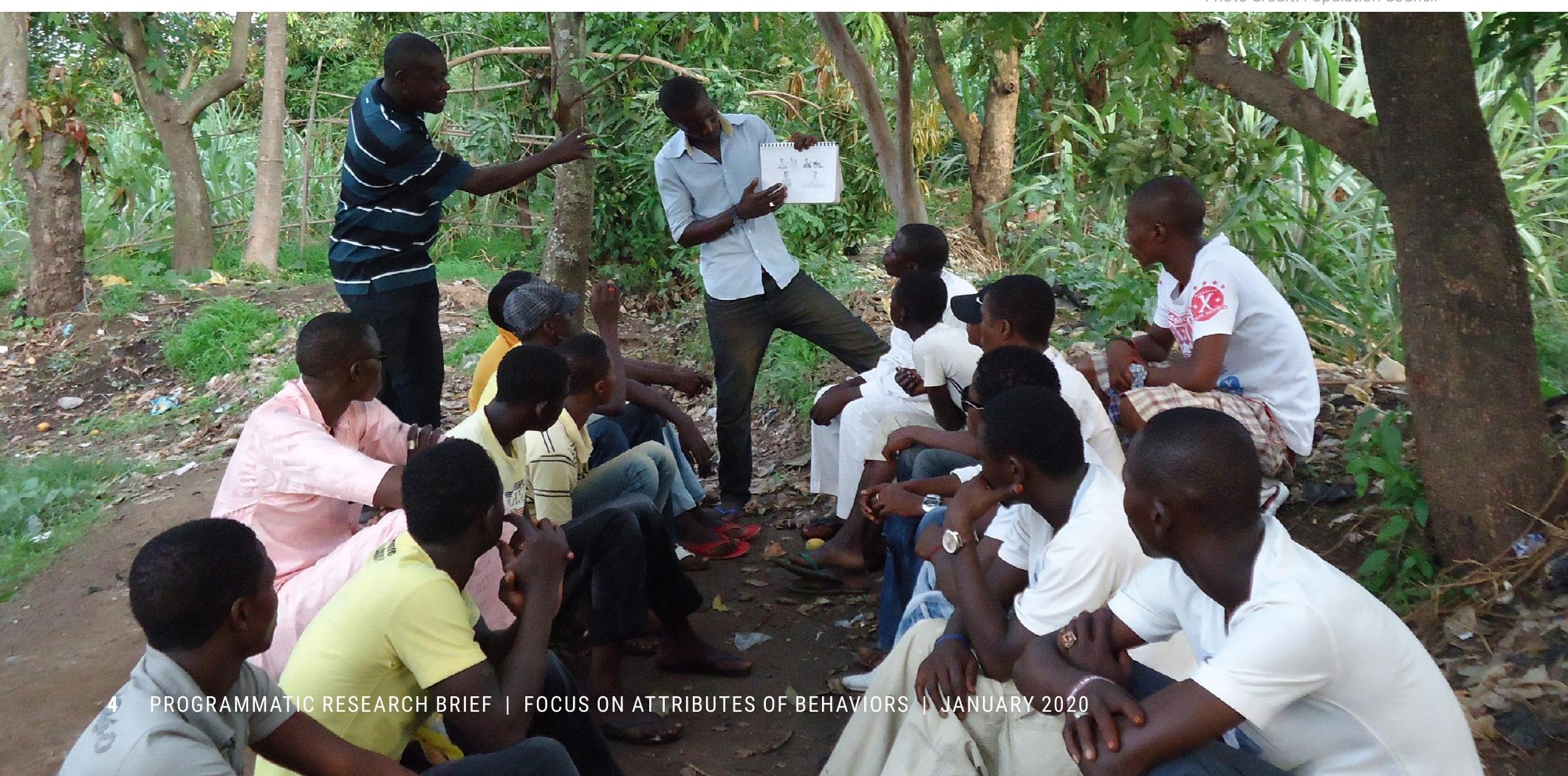


TABLE 3. APPLYING BEHAVIORAL ATTRIBUTES CRITERIA TO SELECT HEALTH OUTCOMES

\author{
Select Accelerator \\ Behavior
}

\section{Caregivers seek full course of timely vaccinations for infants and children under 2 years}

Attribute

Dependency

\section{Time/Opportunity \\ Cost}

Caregivers have to go out of their waygo to a provider or an immunization camp-to enact this behavior

Caregivers need to take each child to a health facility/ immunization camp repeatedly over longtime intervals (e.g., weekly or monthly), and according to a specific schedule
Caregivers need direct assistance from health care providers to achieve this behavioral outcome (e.g., administer the vaccine) someone has to

Caregivers have to make a deliberate decision (either at one or several points) to get a vaccination for each child; they may need additional knowledge about the value of each vaccine, and it may require planning on the part of caregiver to successfully implement the behavior

This behavior has to be repeated over short or long time intervals, and requires women to stick to a schedule and repeatedly decide to effectively use contraceptives

\section{Pregnant women and children sleep under an insecticide treated net}

\begin{abstract}
women or their partners use a modern contracep pregnancy for at least 24 months
\end{abstract}


responsive to interventions that model ideal behaviors or provide training to build appropriate skills, either through interpersonal (e.g., peer-to-peer) or other educational activities? While the review did not yield definitive answers to such questions, it did provide some valuable insights.

- For a behavior that is repeated, but is not dependent on others, is not complex, or does not have a high time/opportunity cost (e.g., insecticide treated bed net use by pregnant women and children), behavior change communication through mass media that includes messages around appropriate/correct use and care of the bed nets have been found to result in improved attitudes and use. This may be because behaviors with this combination of characteristics are particularly susceptible to triggers that remind individuals to continue implementing the behavior, as the primary barrier may be forgetfulness or a lack of immediate or obvious payoffs.

- For a behavior that is repeated and is complex, but is not dependent on others and does not have a time/ opportunity cost (e.g., women or their partners use a modern contraceptive method to avoid pregnancy for at least 24 months after a live birth), successful approaches have incorporated activities that help individuals improve planning skills, including preparing contraceptive plans, helping individuals understand the role contraception can play in determining positive life outcomes and explaining the implications of reproductive health decisions for the future, and included
THIS EXPLORATORY WORK CAN HELP SHIFT OUR THINKING FROM SOLELY A FOCUS ON THE CHARACTERISTICS OF WHO IS DOING A BEHAVIOR OR WHAT OUTCOME WE WANT FROM THAT BEHAVIOR, TO A FOCUS ON HOW INTERVENTIONS CAN BE STRUCTURED TO BEST ADDRESS PARTICULAR ATTRIBUTES OF THE BEHAVIOR ITSELF.

activities that provide mentoring, life goal setting, and motivation to support contraceptive use. This may be because these behaviors require that individuals take a longer-term view to the possible benefits of changing their behavior and that they have a clear understanding of how to effectively implement the behavior.

- For a behavior that needs to be repeated, is complex, dependent on others, and requires time/opportunity
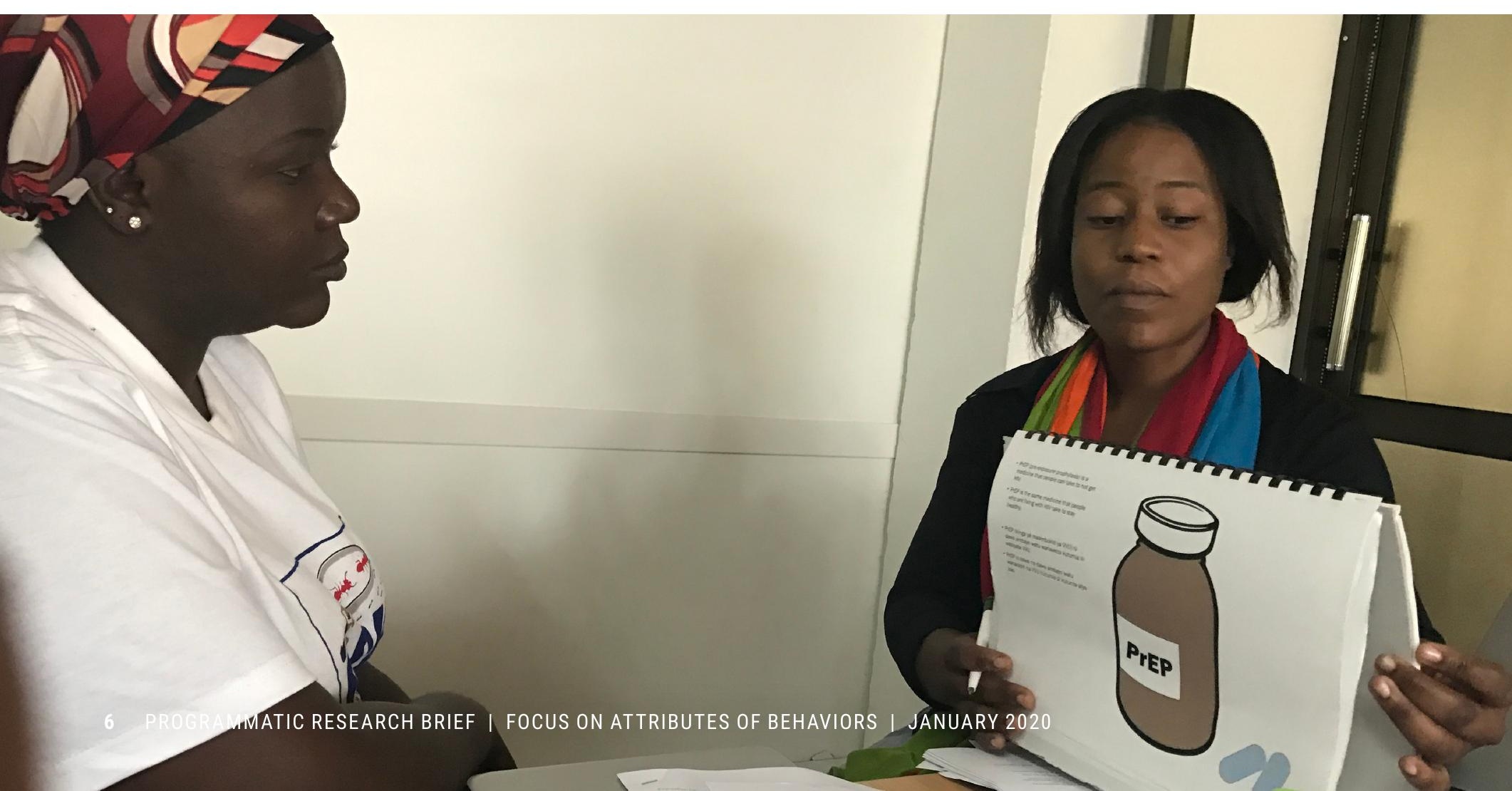
cost (e.g., full course of timely vaccinations for infants and children under two years), patient reminders or recall interventions (e.g., telephone calls, letters, postcards, text messages, or combination of patient reminders and outreach) in combination with facility-based health education and training, and community outreach have been shown to improve immunizations for children. This may be because this combination of behavioral attributes presents a range of programmatic challenges that are not easily addressed through a single approach. Instead, approaches that address the multiple underlying behavioral determinants at multiple levels/touchpoints might be needed.

\section{How can this exploratory work be used in SBC programming?}

This exploratory work can help shift our thinking from a focus solely on the characteristics of who is doing a behavior or what outcome we want from that behavior, to a focus on how interventions can be structured to best address particular attributes of the behavior itself. Some SBC programming already incorporates this type of thinking, for example, providing mobile phone reminders at key points for behaviors that need to be repeated or incentivizing early initiation of breastfeeding through training service providers (including traditional birth attendants) on the benefits this provides newborns. However, it is relatively rare for intervention designs to explicitly acknowledge and address behavioral attributes. It is also not typical to closely examine the role that behavioral attributes may play in shaping the learning processes that people use when developing behavioral patterns or to then apply that knowledge to improving the relevant behavior change mechanisms built into the behavioral change approach. While more research is required to fully understand how behavioral attributes, learning processes, and specific behavioral change mechanisms interact to shape changes in behavior, this review suggests that creating a more deliberate link between these processes may offer a potentially powerful tool to strengthen SBC programming to improve health outcomes. Lastly, expansion of the thinking around behavior attributes and health outcomes, may also want to consider how attributes are considered for non-health behaviors (e.g., civic participation, agriculture). 


\section{Full Evidence Review Report}

Edmeades, Jeffrey and Sanyukta Mathur. 2018.

"Exploration of behavioral attributes for social and behavior change programming," Breakthrough RESEARCH Report. Washington DC: Population Council.

\section{Acknowledgments}

The Breakthrough RESEARCH team would like to thank Arianna Serino, Stephanie Levy, Angela Brasington, Julie Boccanera, and Hope Hempstone for their strategic input and support.

\section{Suggested citation:}

Breakthrough RESEARCH. 2020. "Insights to improve social and behavior change programming through a focus on the attributes of behaviors," Programmatic Research Brief. Washington, DC: Population Council.

\section{Front cover photo credit:}

US Agency for International Development

C2020 The Population Council. All rights reserved.

\section{Email}

\section{BreakthroughResearch@popcouncil.org}

\section{Breakthrough RESEARCH | Population Council}

4301 Connecticut Ave., NW, Suite 280 | Washington, DC 20008

+12022379400 | breakthroughactionandresearch.org

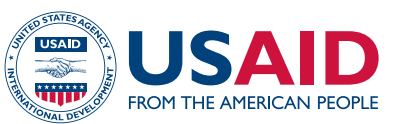

Breakthrough RESEARCH is made possible by the generous support of the American people through the United States Agency for International Development (USAID) under the terms of cooperative agreement no. AIDOAA-A-17-00018. The contents of this document are the sole responsibility of Breakthrough RESEARCH and Population Council and do not necessarily reflect the views of USAID or the United States Government.

\section{POPULATION COUNCIL \\ Ideas. Evidence. Impact.}

The Population Council confronts critical health and development issues-from stopping the spread of HIV to improving reproductive health and ensuring that young people lead full and productive lives. Through biomedical, social science and public health research in about 50 countries, the Council works with our partners to deliver solutions that lead to more effective policies, programs, and technologies to improve lives worldwide. Established in 1952 and headquartered in New York, the Council is a nongovernmental, nonprofit organization with an international board of trustees.

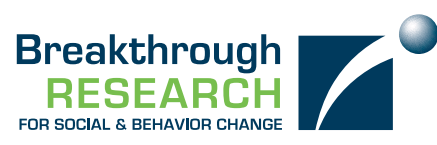

Breakthrough RESEARCH catalyzes social and behavior change (SBC) by conducting state-ofthe-art research and evaluation and promoting evidence-based solutions to improve health and development programs around the world. Breakthrough RESEARCH is a consortium led by the Population Council in partnership with Avenir Health, ideas42, Institute for Reproductive Health at Georgetown University, Population Reference Bureau, and Tulane University. 